\title{
Optimization of Magnetizing Reduction and Magnetic Separation of Iron Ores by Experimental Design
}

\author{
M. I. NASR and M. A. YOUSSEF \\ Central Metallurgical Research and Development Institute, CMRDI, P. O. Box 87 Helwan, Cairo, Egypt.
}

(Received on October 12, 1995; accepted in final form on March 4, 1996)

\begin{abstract}
An experimental design of magnetizing reduction and magnetic separation of Egyptian low grade iron ore has been conducted using a data developed from applying the conventional single-factor experimentation in order to get the real optimum conditions of the processing. A model has been developed for magnetizing reduction to describe the relationship between the extent of reduction and the reduction temperature, time and reducing gas flow rate, whereas another model for magnetic separation process was deduced correlating the ore size and reduction time to the iron recovery in the magnetic concentrate.
\end{abstract}

KEY WORDS: experimental design; magnetizing reduction; magnetic separation; iron ores; factorial design; gaseous reduction.

\section{Introduction}

Investigators conducting experimental programs are most often confronted with the problem of determining the possible effect of a specific number of factors. In such situations, it is necessary to establish an acceptable procedure for choosing the conditions of each experimental run. In the traditional approach to experimentation involving a large number of factors, it is normal to vary one factor while holding all the others constant to determine the effect of that factor. The experiment is then repeated for all other factors, each time holding all others constant except the one being studied. According to this widespread single-factor experimentation, the optimum values of the different factors (calculated individually) are listed as the conditions recommended to achieve the optimum values of the goals of experimentation. On the other hand, experimental design shows the expediency of simultaneously varying all the factors under investigation. The design of an experiment is the procedure of selecting the number of trials and conditions for running them, essential and sufficient for solving the problem that has been set with the required precision. It is proposed that an investigator organizes cosecutive small series of trials, in each of which all the factors are simultaneously varied according to definite rules. The series are so organized that after mathematical processing of a preceding one it will be possible to select the conditions for conducting the following series. Thus sequentially, step by step, is the optimum reached. Some other features are minimizing the total number of trials, simultaneous variation of all the variables determining the process according to special rules called algorithms, the use of mathematical relation formalizing many actions of the experimenter and, finally, the selection of a clear-cut strategy that helps to make substantiated decisions after each series of experiments.

In the present study, Egyptian iron ores from Bahariya Oasis are subjected to magnetizing reduction followed by magnetic separation in order to get rid of gangue minerals and produce iron ore concentrate suitable for ironmaking operations. The experiments were conducted according to the traditional single-factor experimentation followed by applying the experimental design technique in order to get the real optimum conditions of processing.

\section{Previous Work}

Magnetizing reduction is one of the most effective unit operations in the treatment of iron ores specially those which are poorly responsive to conventional beneficiation techniques. It involves the conversion of feably magnetic iron minerals in the ore to the strongly magnetic form by subjecting the ore to a reducing atmosphere at elevated temperatures. The resulting artificial magnetite (or $\gamma$-hematite) is separated from the non-magnetic gangue by magnetic separation. Although many investigators $^{1-5)}$ studied the reduction of iron ores and oxides, a relatively less attention has been given to the magnetizing reduction process. ${ }^{6-8)}$ The following part outlines the main findings of some of the hematitemagnetite reduction work cited in the literature. ElAbdouni et al. ${ }^{9)}$ studied the changes in the texture during the reduction of hematite to magnetite at $650^{\circ} \mathrm{C}$ with $\mathrm{CO} / \mathrm{CO}_{2}$ as reducing gas. They found that during the reduction of $\alpha-\mathrm{Fe}_{2} \mathrm{O}_{3}$ the structural organization of magnetite $\mathrm{Fe}_{3} \mathrm{O}_{4}$ changes and leads to a physical structure of the product which is different from the magnetite layer. These observations accounted for the kinetic 
behaviour of the reduction rate in which gaseous diffusion coefficient is not constant in the magnetite layer. Adam et al. ${ }^{10)}$ reported on the cracking of hematite crystals during their reduction into magnetite, typically at $350^{\circ} \mathrm{C}$ with $\mathrm{CO} / \mathrm{CO}_{2}=20 / 80$ and studied the influence of temperature and of the $\mathrm{CO} / \mathrm{CO}_{2}$ ratio and investigated the magnitude of the stresses. They showed that the fracture mechanism is linked with the first steps of the reaction and investigated the processes which direct the nucleation frequency and the distribution of the magnetite nuclei over the hematite surface. They also found that water vapour has a sticking effects such as quasi-suppression of the cracking and of the induction period, a rather uniform distribution of small nuclei, a decreased rate of reduction for any given reacting fraction even for trace amounts of water $\left(p_{\mathrm{H}_{2} \mathrm{O}} 1\right.$ torr). ElTabirou et al. ${ }^{11)}$ in a contribution for elucidating the discrepancies among authors as regards the transition between porous and lamellar magnetites carried out a wide series of experiments with single crystals over a large range of temperatures $\left(400-1000^{\circ} \mathrm{C}\right)$ and $\mathrm{CO}$ content $(2-50 \%)$. They established that lamellar magnetite is favoured by high temperature and low CO content. This is explained by consideration of the conditions governing the competition between cation diffusion in the semi-coherent hematite-magnetite interface and chemical reaction rate. At low temperatures, the crystals are severely fractured, because hematite is not plastic enough, especially at a high $\mathrm{CO}_{2}$ content. $\mathrm{Nasr}^{12)}$ studied the effect of temperature and time on the structure of magnetite produced by reduction of hematite with hydrogen at low temperature. He proposed a conceptual mechanism to elucidate both densification and porous structure development as influenced by temperature. $\mathrm{He}$ also made a comparative study on the effect of reduction temperature and time on the structure of hematite and magnetite.

On the other hand, very few investigations using experimental design have been published ${ }^{13-16)}$ but none of them applied this experimentation technique on magnetizing reduction and magnetic separation. Magnetizing reduction followed by magnetic separation is a compound technique for beneficiation of iron ores. Optimization of each of the reduction and separation process will have a considerable effect on improving the efficiency of this beneficiation technique. The aim of the present work is to investigate how successful experimental design can be used for optimizing such compound beneficiation process. Also, this study presents a comparative analysis of the results of conventional experimentation and those obtained when experimental design was used for optimization of magnetizing reduction and magnetic separation of an Egyptian iron ore.

\section{Experimental}

\subsection{Chemical Analysis and Mineralogy}

A sample of the Egyptian iron ores (Bahariya Oasis) used in the present study has the chemical analysis shown in Table 1. X-ray diffraction analysis shows that it is mainly composed of hydrogoethite, $\alpha$-goethite, $\alpha$ hematite, hydrated iron oxide and psilomelane as the main manganese mineral as well as some quartz, barite, halites and dolomite. Photomicrographs for the polished sections of the ore sample are shown in Figs. 1(a) and 1(b). It shows that the sample is constituted of goethite and hematite intimately mixed with different manganese minerals. Goethite generally forms botryoidal, oolitic masses or spindle-shaped crystals sometimes associated with hematite, crystomelane and psilomelane. Hematite forms tabular, fibrous aggregates in the form of oolites and pisolites cemented with quartz and calcite. Psilomelane exhibits a colloform texture which may contain some cryptomelane and pyrolusite. Sometimes it forms botryoides, the interspaces between them are filled with calcite or quartz. Cryptomelane forms pockets and bands of needle-shaped crystals which may exhibit fan-shaped texture. Its bands intercalate with others of psilomelane, goethite and pyrolusite. Finally, pyrolusite is found as separate outer bands in the manganese botryoids and commonly occurs as stalactic

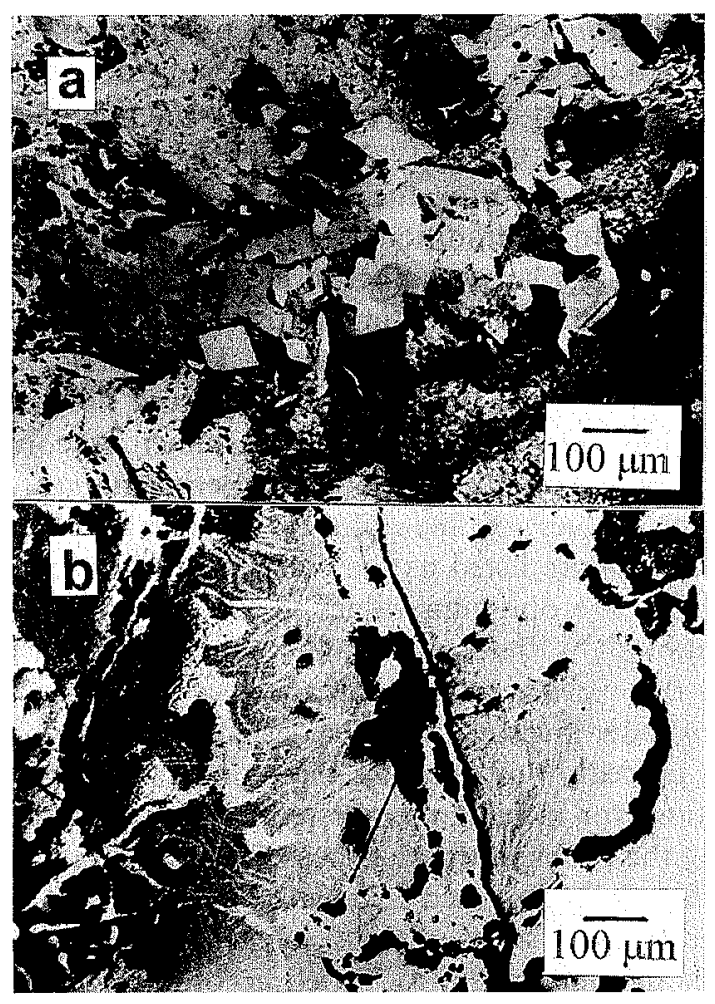

Fig. 1. Photomicrograph for the iron ore used in the study: (a) Section showing hematite, calcite and quartz. (b) Section showing iron minerals and pyrolusite.

Table 1. Chemical analysis of the iron ore sample.

\begin{tabular}{|c|c|c|c|c|c|c|c|c|c|c|}
\hline Constituent & $\mathrm{Fe}$ & $\mathrm{Mn}$ & $\mathrm{SiO}_{2}$ & $\mathrm{Al}_{2} \mathrm{O}_{3}$ & $\mathrm{CaO}$ & $\mathrm{MgO}$ & $\mathrm{P}_{2} \mathrm{O}_{5}$ & $\mathrm{SO}_{3}{ }^{\circ}$ & Loss on ignition & Moisture \\
\hline Assay (\%) & 49.24 & 7.13 & 2.55 & 2.66 & 4.47 & 0.67 & 0.055 & 1.03 & 8.25 & 1.42 \\
\hline
\end{tabular}


aggregates or tabular crystals forming spheroids encountered within the other manganese minerals.

\subsection{Apparatus}

The reduction system, as shown in Fig. 2, consists of three main parts; gas purification and controlling system, the fluidized bed reactor and absorption system for gaseous products. Two gas trains are used; one for hydrogen and the other for nitrogen, meeting at the entrance of the transparent silica reaction tube. The trains include essentially the appropriate gas purification units, flowmeters and flow regulators. The fluidized bed reactor is $70 \mathrm{~cm}$ long and $3.5 \mathrm{~cm}$ inner diameter silica tube with a sintered silica disc fixed at $40 \mathrm{~cm}$ from the bottom to support the solid charge. The reactor is externally heated by a tube furnace which has a constant hot zone extends $5 \mathrm{~cm}$ below and above the fluidized bed. The temperature is measured inside the fluidized bed by chromel-alumel thermocouple. The lower part of the silica tube is filled with silica wool to help in preheating the gas. Anhydrous calcium chloride filled U-tubes were used for collecting water vapour produced from the reaction and care was taken to prevent any condensation in the upper part of the reaction tube and the tubes leading to the U-tubes by the use of heating bands. Inside the reactor, just above the sintered disc there is a tube for blowing a high current of cold hydrogen to quench the reduced iron ore and thus stop the progress of reaction.

\subsection{Reduction Procedure}

Runs were conducted on $50 \mathrm{~g}$ ore charged at temperatures ranging between 400 and $500^{\circ} \mathrm{C}$. The particle sizes worked on were $-0.5+0.25,-0.25+0.125$ and $-0.125 \mathrm{~mm}$ and the hydrogen flow rates were 2,3 and $4 l /$ min at NTP. After switching on the furnace, nitrogen was allowed to pass through the apparatus until the required temperature in the reactor is obtained and fixed to within $\pm 2{ }^{\circ} \mathrm{C}$. The progress of reduction was followed by weighing the absorption U-tubes at the pre-determined time intervals and the cumulative weight loss-time relations can be obtained. At the end of the experiment, the reduction was stopped by passing a high flow rate of cold hydrogen. The cold reduced mass was discharged into acetone to prevent reoxidation by air, then ground to $-0.125+0.057 \mathrm{~mm}$ for magnetic separation.

\subsection{Magnetic Separation}

Magnetic separation was carried out using Davistube tester as a magnetic separator under the following conditions: 230 stroke/min, 1 ampere current, $0.3 \mathrm{l} / \mathrm{min}$ water flow rate and $5 \mathrm{~min}$ time of agitation. Cleaning was carried out for the non-magnetic fraction using the same conditions but the time for agitation was only 3 min.

\section{Results and Discussion}

\subsection{Magnetizing Reduction}

Iron ore samples of the size $-0.5+0.25 \mathrm{~mm}$ were subjected to reduction with $\mathrm{H}_{2}$ at a flow rate of $3 \mathrm{l} / \mathrm{min}$ at 400,450 and $500^{\circ} \mathrm{C}$ for $30 \mathrm{~min}$. The magnetic fractions of the reduced samples were separated and subjected to chemical analysis to determine the iron and manganese contents; the results are given in Figs. 3 and 4. The reproducibility of weight loss and $\mathrm{Fe}$ recovery are in the range of $2 \%$, each run was repeated three times and the results given in the figures represent the mean values. It is clear that at a given reduction temperature iron recovery in the magnetic fraction exhibits a sharp increase at the onset of reduction (1-2 min) and keeps its high value (>90\%) for $10-11 \mathrm{~min}$ then slowly declines. Figure 3 also indicates that manganese content is greatly affected by the magnetizing reduction treatment where it decreases from $7 \%$ in the ore to $2.6-1.7 \%$ in the magnetic

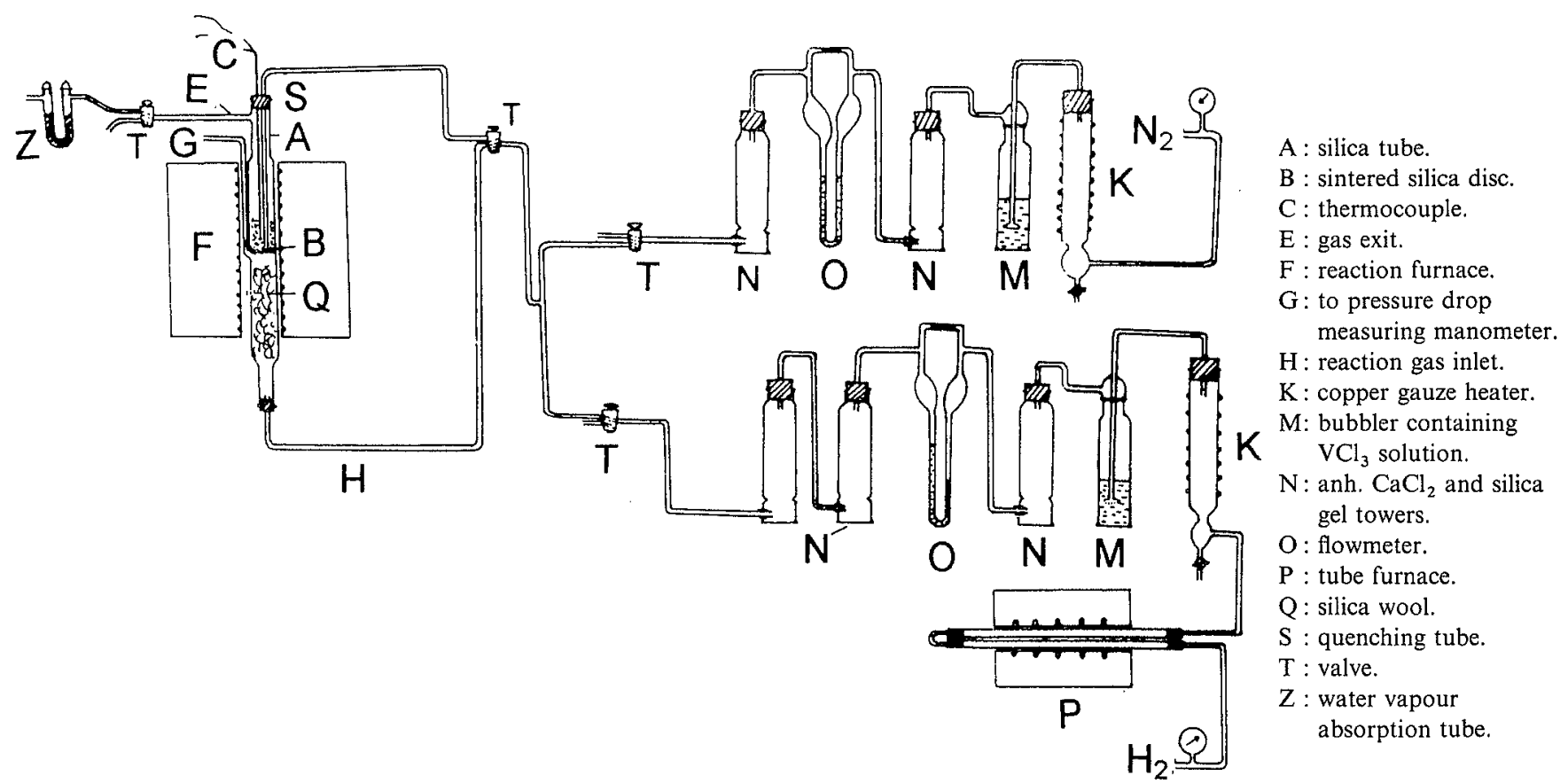

Fig. 2. Schematic diagram for the reduction system. 


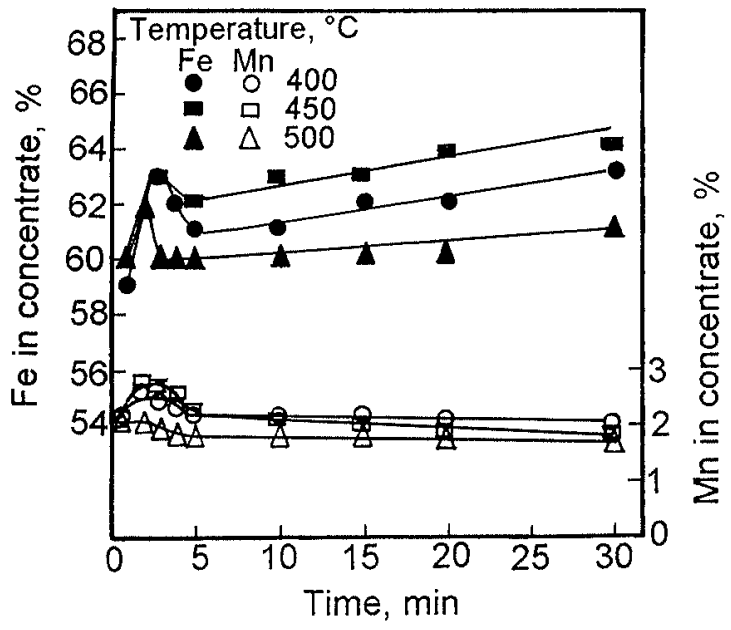

Fig. 3. Effect of reduction temperature on $\mathrm{Fe}$ and $\mathrm{Mn}$ contents in magnetic fraction.

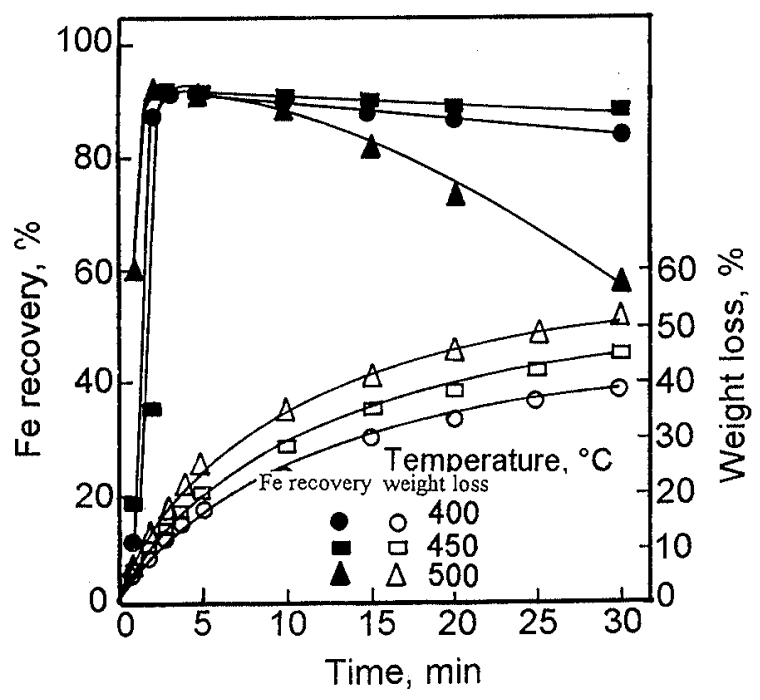

Fig. 4. Effect of reduction temperature on Fe recovery and weight loss during magnetizing reduction.

fraction. For samples reduced at 400 and $450^{\circ} \mathrm{C}$ manganese content shows a slight increase after a reduction lapse of $2 \mathrm{~min}$ then decreases at longer periods of reduction, whereas at $500^{\circ} \mathrm{C}$ manganese content starts to decrease directly at the onset of reduction. Bearing in mind that one of the main aims of the ore treatment is to remove as much as possible of manganese from the ore and, at the same time, not to lose iron in the non-magnetic fraction, it is obvious that we are looking for the magnetizing reduction conditions which result in high values for both iron recovery and content as well as low value of manganese content in the magnetic fraction. According to traditional experimentation, Fig. 4 shows that the highest value of iron recovery $(93 \%)$ is achieved for samples reduced at $400^{\circ} \mathrm{C}$ for $4 \mathrm{~min}$, at $450^{\circ} \mathrm{C}$ for $3 \mathrm{~min}$ and at $500^{\circ} \mathrm{C}$ for $2 \mathrm{~min}$. Figure 4 also shows that the highest values of weight loss are achieved for samples reduced at $450-500^{\circ} \mathrm{C}$ for $25-30 \mathrm{~min}$. It is clear that with the conventional experimentation method it is difficult to determine the process conditions which make weight loss and $\mathrm{Fe}$ recovery optimum. On the other hand, the highest value of iron content $(64 \%)$ is

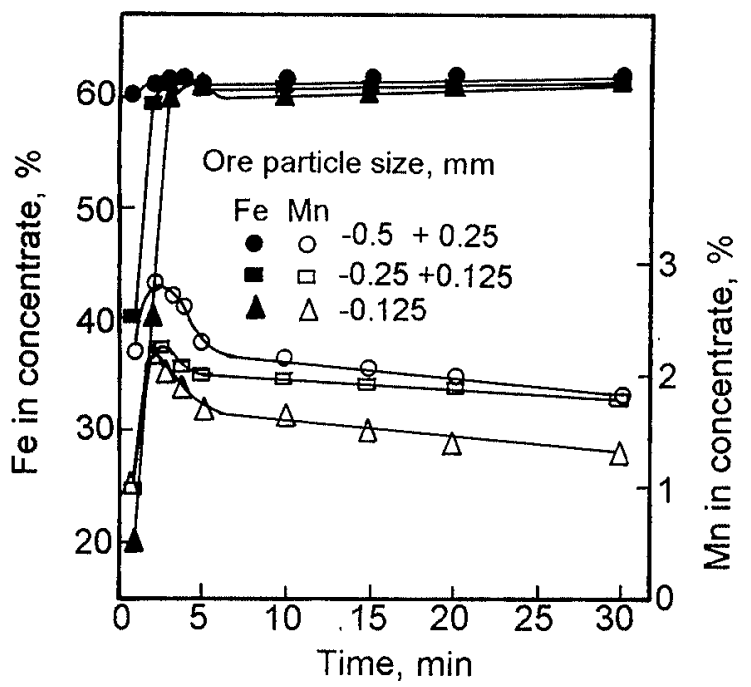

Fig. 5. Effect of ore particle size on $\mathrm{Fe}$ and $\mathrm{Mn}$ contents in magnetic fraction for samples reduced at $450^{\circ} \mathrm{C}$.

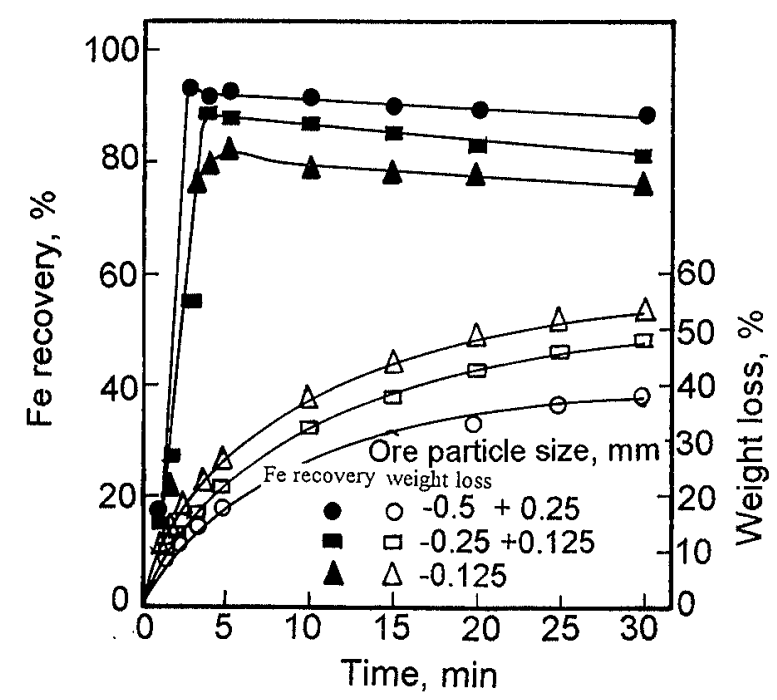

Fig. 6. Effect of ore particle size on Fe recovery and weight loss during magnetizing reduction at $450^{\circ} \mathrm{C}$.

obtained for samples reduced at $450^{\circ} \mathrm{C}$ for 20 or $30 \mathrm{~min}$ whereas samples reduced at $500^{\circ} \mathrm{C}$ for 20 or $30 \mathrm{~min}$ have the lowest value of manganese content $(1.7 \%)$. Although the above results are valid only when the ore size and reducing gas flow rate are kept constant at $-0.5+0.25$ $\mathrm{mm}$ and $3 l / \mathrm{min}$ respectively, they show a more or less wide discrepancy. The temperature of reduction lies in the range $400-500^{\circ} \mathrm{C}$ while the time varied from 2 to $30 \mathrm{~min}$. Accordingly, no optimum specific values of reduction temperature or duration can be concluded out of the above mentioned results.

In order to investigate the effect of iron ore particle size on the magnetizing reduction treatment, reduction was carried out at $450^{\circ} \mathrm{C}$ using $\mathrm{H}_{2}$ at a flow rate of 3 $\mathrm{l} / \mathrm{min}$ for samples having the following size ranges $-0.5+$ $0.25,-0.25+0.125$ and $-0.125 \mathrm{~mm}$. The results of these runs are given in Figs. 5 and 6. It indicates that the highest iron recovery $(93 \%)$ is obtained for the largest size fraction reduced for $3 \mathrm{~min}$ and decreases for lower sizes which produce higher values of weight loss. On the other hand, the lowest manganese content $(1.3 \%)$ can 
Table 2. Phases identified by X-ray diffraction of reduced samples.

\begin{tabular}{|c|c|c|}
\hline $\begin{array}{l}\text { Reduction } \\
\text { temp., }{ }^{\circ} \mathrm{C}\end{array}$ & $\begin{array}{l}\text { Reduction } \\
\text { time, min }\end{array}$ & Phases \\
\hline 450 & 2 & $\mathrm{Fe}_{2} \mathrm{O}_{3}, \mathrm{Fe}_{3} \mathrm{O}_{4}, \mathrm{Mn}_{2} \mathrm{O}_{3}, \mathrm{MnO}, \mathrm{SiO}_{2}$ \\
\hline 450 & 5 & $\mathrm{Fe}_{2} \mathrm{O}_{3}, \mathrm{Fe}_{3} \mathrm{O}_{4}, \mathrm{MnO}, \mathrm{SiO}_{2}$ \\
\hline 450 & 10 & $\mathrm{Fe}_{2} \mathrm{O}_{3}, \mathrm{Fe}_{3} \mathrm{O}_{4}, \mathrm{MnO}, \mathrm{SiO}_{2}$ \\
\hline 450 & 20 & $\mathrm{Fe}_{2} \mathrm{O}_{3}, \mathrm{Fe}_{3} \mathrm{O}_{4}, \mathrm{MnO}, \mathrm{SiO}_{2}$ \\
\hline 450 & 30 & $\mathrm{Fe}_{3} \mathrm{O}_{4}, \mathrm{MnO}, \mathrm{SiO}_{2}, \mathrm{Fe}$ \\
\hline 500 & 2 & $\mathrm{Fe}_{2} \mathrm{O}_{3}, \mathrm{Fe}_{3} \mathrm{O}_{4}, \mathrm{MnO}, \mathrm{SiO}_{2}$ \\
\hline 500 & 5 & $\mathrm{Fe}_{2} \mathrm{O}_{3}, \mathrm{Fe}_{3} \mathrm{O}_{4}, \mathrm{MnO}, \mathrm{SiO}_{2}$ \\
\hline 500 & 10 & $\mathrm{Fe}_{2} \mathrm{O}_{3}, \mathrm{Fe}_{3} \mathrm{O}_{4}, \mathrm{MnO}, \mathrm{SiO}_{2}$ \\
\hline 500 & 20 & $\mathrm{Fe}_{3} \mathrm{O}_{4}, \mathrm{MnO}, \mathrm{SiO}_{2}, \mathrm{Fe}$ \\
\hline 500 & 30 & $\mathrm{Fe}_{3} \mathrm{O}_{4}, \mathrm{MnO}, \mathrm{SiO}_{2}, \mathrm{FeO}, \mathrm{Fe}$ \\
\hline
\end{tabular}

be observed for the fine ore $(-0.125 \mathrm{~mm})$ reduced for $30 \mathrm{~min}$. It is clear that the experimental conditions which result in highest iron recovery is different from those producing lowest manganese content in the magnetic fraction. Again determining the optimum magnetizing reduction conditions is getting more ambiguous, since we can not decide which ore size can be selected and for how long should it be reduced out of the results given in Figs. 5 and 6 for reduction at $450^{\circ} \mathrm{C}$ using $3 \mathrm{l} / \mathrm{min}$ hydrogen. The above results indicate the difficulty of giving the process conditions which make reduction ratio and $\mathrm{Fe}$ recovery optimum by means of conventional experimentation method.

The problem is getting more complicated when a range of reducing gas flow rates is also considered. It is conceived that high reduction temperature as well as small iron ore size and, to a certain extent, higher rate of reducing gas flow lead to a larger reduction extent. This is favourable as long as hematite is being reduced to magnetite and that the magnetite-wustite conversion step has not been reached. Table 2 indicates the phases present in the samples reduced at 450 and $500^{\circ} \mathrm{C}$ for different periods. It can be easily noticed that at $450^{\circ} \mathrm{C}$, some hematite grains are still unreduced even for a reduction time of $20 \mathrm{~min}$ whereas at $30 \mathrm{~min}$ all hematite has been converted to magnetite. On the other hand, $\mathrm{MnO}_{2}$ in the ore samples has been converted quickly to the non-magnetic phases $\mathrm{Mn}_{2} \mathrm{O}_{3}$ and $\mathrm{MnO}$, while quartz is kept unaffected. As reduction temperature increases to $500^{\circ} \mathrm{C}$, hematite is totally converted to magnetite in samples reduced for $20 \mathrm{~min}$. In the samples reduced for $30 \mathrm{~min}$, Table 2 shows that the non-magnetic ferrous oxide (wustite) phase has been developed which means that over-reduction of hematite took place with the consequent lowering of iron recovery in the magnetic phase.

The above results show that the magnetizing reduction process has been physically carried out, and we are confronted with the task of optimizing it.

\subsection{Experimental Design}

Among the many possible ways of finding the optimal conditions, the present study shall consider one that has been named Box-Wilson method or the method of steepest ascent. This method allows for obtaining statistical mathematical models of the process using factorial design, regression analysis and movement along the gradient. Few assumptions have to be made beforehand, such as, the problem permits one optimization parameter to be selected, a set of determining factors will be selected such that each of the factors is controllable, the results of the trials are reproducible and finally the mathematical model of the process is not known. In the present work, two processes will be optimized, these are magnetizing reduction and magnetic separation. Optimization of magnetizing reduction gives the optimum experimental conditions for converting hematite in the iron ore to magnetite which in turn is to be separated magnetically. Therefore, reduction ratio is a good optimization parameter for measuring the efficiency of conversion in the magnetizing reduction process. On the other hand, when reduced samples are subjected to magnetic separation and $\mathrm{Fe}$ recovery is chosen as optimization parameter, both the degree of reduction and the efficiency of magnetic separation technique will affect the process. That is because optimization of magnetic separation process will, in one way or another, be affected by the efficiency of the magnetic separation technique. In case of using highly efficient magnetic separation technique, the optimization of magnetic separation will give conditions more or less similar to the optimized conditions for magnetizing reduction. On the other hand, if there is a wide discrepancy between the optimized conditions for magnetizing reduction and those for magnetic separation, this will mean that the magnetic separation technique is not operating well or not suitable for the process.

\subsection{Optimization of Magnetizing Reduction Conditions}

The specific objective of magnetizing reduction is to convert the feably magnetic iron oxide phase hematite to the strongly magnetic one magnetite. Therefore, the weight loss percent $(Y)$, which is a sum of $\mathrm{O}_{2}$ removed during reduction of iron and manganese oxides together with moisture and loss on ignition with respect to total reducible $\mathrm{O}_{2}$ in the sample, was selected as the optimization parameter given that the reduction of hematite is confined to magnetite. In this domain, weight loss percent is a good optimization parameter since it effectively reflects the response to the actions of the experimental factors, besides that it is a simple number that can be easily calculated. Four experimental variables (factors) namely, reduction temperature $\left(X_{1}\right)$, reduction time $\left(X_{2}\right)$, gas flow rate $\left(X_{3}\right)$ and ore particle size $\left(X_{4}\right)$ were allowed to vary simultaneously, and the other conditions including quantity of the ore and type of reducing gas were kept constant. The basic levels of these factors were chosen as follows:

- reduction temperature $X_{1}^{\circ}=450^{\circ} \mathrm{C}$

- time of reduction $X_{2}^{\circ}=20 \mathrm{~min}$

- gas flow rate $X_{3}^{\circ}=3 l / \mathrm{min}$

- ore particle size $X_{4}^{\circ}=0.25-0.125 \mathrm{~min}$ 
In order to avoid over-reduction of magnetite to wustite, relatively narrow boundaries of the regions of determination of the factors were experimentally considered. Accordingly, the upper and lower levels of the factors are:

$$
\begin{array}{llll}
X_{1} & 400,500^{\circ} \mathrm{C} & X_{2} & 10,30 \mathrm{~min} \\
X_{3} & 2,4 l / \mathrm{min} & X_{4} & 0.5-0.125,-0.125 \mathrm{~mm}
\end{array}
$$

That is, the variation intervals of the factors are:

$$
\begin{array}{ll}
\Delta X_{1}=50^{\circ} \mathrm{C} & \Delta X_{2}=10 \mathrm{~min} \\
\Delta X_{3}=1 \mathrm{l} / \mathrm{min} & \Delta X_{4}=0.125 \mathrm{~mm}
\end{array}
$$

(where the mean diameters were used as the representative diameters of $X_{4}^{\circ}$ and $X_{4}$ )

It is clear that the selection of the experimental region of factor space was directly connected with the detailed analysis of the experimental results of the already performed runs. In the light of the above outlined design, the number of trials will be equal to the number of levels of the factors, i.e. 2, raised to a power equals to the number of factors, i.e. 4, that comes up with 16 trials. The different trials together with the values of factors and the corresponding optimization parameters are listed in Table 3 . As one of the main advantages of experimental design, the interaction effects between two, three and four factors are considered as follows:

-6 two-factor interactions:

$$
\begin{array}{lll}
X_{5}=X_{1} X_{2} & X_{6}=X_{1} X_{3} & X_{7}=X_{1} X_{4} \\
X_{8}=X_{2} X_{3} & X_{9}=X_{2} X_{4} & X_{10}=X_{3} X_{4}
\end{array}
$$

-4 three-factor interactions:

$$
\begin{array}{ll}
X_{11}=X_{1} X_{2} X_{3} & X_{12}=X_{1} X_{2} X_{4} \\
X_{13}=X_{1} X_{3} X_{4} & X_{14}=X_{2} X_{3} \mathrm{X}_{4}
\end{array}
$$

-1 four-factor interaction:

$$
X_{15}=X_{1} X_{2} X_{3} X_{4}
$$

For movement toward the optimum point we need a model that can accurately describe the process, this model is linear if the factors are independent and nonlinear when factors interactions are considered. In the latter case, relatively too many coefficients have to be calculated. A design matrix can be developed, as shown in Table 4, in which the number of rows is equal to the number of trials, $N$, and the number of columns is equal to the number of both the single and multiple factors, $k$, plus one more column. The extra column (denoted $X_{0}$ in Table 4) is augmented to the matrix in order to be used for calculating the independent factor in the model. The total number of columns in the design matrix sums up to $k+1$ which is equal to the number of model coefficients. Each cell in the design matrix contains either

Table 3. Values of experimental factors and the corresponding optimization parameter for magnetizing reduction.

\begin{tabular}{|c|c|c|c|c|c|}
\hline & \multicolumn{5}{|c|}{ Experimental factors } \\
\hline Trial no. & $X_{1}$ & $X_{2}$ & $X_{3}$ & $X_{4}$ & $X$ \\
\hline 1 & 500 & 10 & 2 & 0.125 & 23 \\
\hline 2 & 500 & 10 & 2 & $0.5-0.125$ & 27 \\
\hline 3 & 500 & 10 & 4 & 0.125 & 31 \\
\hline 4 & 500 & 10 & 4 & $0.5-0.125$ & 35 \\
\hline 5 & 500 & 30 & 2 & 0.125 & 45 \\
\hline 6 & 500 & 30 & 2 & $0.5-0.125$ & 49 \\
\hline 7 & 500 & 30 & 4 & 0.125 & 51 \\
\hline 8 & 500 & 30 & 4 & $0.5-0.125$ & 55 \\
\hline 9 & 400 & 10 & 2 & 0.125 & 20 \\
\hline 10 & 400 & 10 & 2 & $0.5-0.125$ & 23 \\
\hline 11 & 400 & 10 & 4 & 0.125 & 23 \\
\hline 12 & 400 & 10 & 4 & $0.5-0.125$ & 27 \\
\hline 13 & 400 & 30 & 2 & 0.125 & 33 \\
\hline 14 & 400 & 30 & 2 & $0.5-0.125$ & 37 \\
\hline 15 & 400 & 30 & 4 & 0.125 & 45 \\
\hline 16 & 400 & 30 & 4 & $0.5-0.125$ & 49 \\
\hline
\end{tabular}

Table 4. Design matrix for magnetizing reduction.

\begin{tabular}{|c|c|c|c|c|c|c|c|c|c|c|c|c|c|c|c|c|c|}
\hline Trial no. & $\mathrm{X}_{0}$ & $\mathrm{X}_{1}$ & $\mathrm{X}_{2}$ & $\mathrm{X}_{3}$ & $\mathrm{X}_{4}$ & $\mathrm{X}_{5}$ & $\mathrm{X}_{6}$ & $\mathrm{X}_{7}$ & $\mathrm{X}_{8}$ & $\mathrm{X}_{9}$ & $\mathrm{X}_{10}$ & $\mathrm{X}_{11}$ & $\mathrm{X}_{12}$ & $\mathrm{X}_{13}$ & $\mathrm{X}_{14}$ & $\mathrm{X}_{15}$ & $\mathrm{Y}$ \\
\hline 1 & + & + & - & - & - & - & - & - & + & + & + & + & + & + & - & - & 23 \\
\hline 2 & + & + & - & - & + & - & - & + & + & - & - & + & - & - & + & + & 27 \\
\hline 3 & + & + & - & + & - & - & + & - & - & + & - & - & + & - & + & + & 31 \\
\hline 4 & + & + & - & + & + & - & + & + & - & - & + & - & - & + & - & - & 35 \\
\hline 5 & + & + & + & - & - & + & - & - & - & - & + & - & - & + & + & + & 45 \\
\hline 6 & + & + & + & - & + & + & - & + & - & + & - & - & + & - & - & - & 49 \\
\hline 7 & + & + & + & + & - & + & + & - & + & - & - & + & - & - & - & - & 51 \\
\hline 8 & + & + & + & + & + & + & + & + & + & + & + & + & + & + & + & + & 55 \\
\hline 9 & + & - & - & - & - & + & + & + & + & + & + & - & - & - & - & + & 20 \\
\hline 10 & + & - & - & - & + & + & + & - & + & - & - & - & + & + & + & - & 23 \\
\hline 11 & + & - & - & + & - & + & - & + & - & + & - & + & - & + & + & - & 23 \\
\hline 12 & + & - & - & + & + & + & - & - & - & - & + & + & + & - & - & + & 27 \\
\hline 13 & + & - & + & - & - & - & + & + & - & - & + & + & + & - & + & - & 33 \\
\hline 14 & + & - & + & - & + & - & + & - & - & + & - & + & - & + & - & + & 37 \\
\hline 15 & + & - & + & + & - & - & - & + & + & - & - & - & + & + & - & + & 45 \\
\hline 16 & + & - & + & + & + & - & - & - & + & + & + & - & - & - & + & - & 49 \\
\hline
\end{tabular}


+ or - which means the upper or lower level of the factor respectively. The matrix design helps in calculating the mathematical model coefficients according to the following formula:

$$
a_{j-1}=\left\{\sum_{i=1}^{N} X_{i j} Y_{i}\right\} / N, \quad j=1,2, \cdots, k+1
$$

where, $\quad a$ : coefficient value,

$i$ and $j$ : number of row and column respectively in the design matrix.

The regression model equation can be written as follows:

$$
Y=a_{0}+a_{1} X_{1}+a_{2} X_{2}+\cdots+a_{k} X_{k}
$$

The values of the calculated coefficients are:

$$
\begin{array}{llll}
a_{0}=35.81 & a_{1}=3.69 & a_{2}=9.69 & a_{3}=3.69 \\
a_{4}=1.94 & a_{5}=0.81 & a_{6}=-0.19 & a_{7}=0.06 \\
a_{8}=0.81 & a_{9}=0.06 & a_{10}=0.06 & a_{11}=-1.31 \\
a_{12}=-0.06 & a_{13}=-0.06 & a_{14}=-0.06 & a_{15}=0.06
\end{array}
$$

\subsection{Testing the Significance of Coefficients}

The significance of each coefficient is tested separately. The statistical "Student' $s$ " $t$ method at $5 \%$ significance level is used in the present study. It is first of all necessary to find the variance of the regression coefficient $v_{\mathrm{c}}^{2}$. In our case it is determined by the formula

$$
v_{\mathrm{c}}^{2}=v_{\mathrm{r}}^{2} / N
$$

where $v_{\mathbf{r}}^{2}$ is the variance of reproducibility with its own number of degrees of freedom. The formula clearly indicates that the variances of all coefficients are equal to one another since they depend only on the error of the experiments and the number of trials. The confidence interval $\Delta b_{j}$ is calculated as follows;

$$
\Delta b_{j}= \pm t v_{\mathrm{c}}
$$

where $t$ is the tabulated value of "Student's" criterion for the number of degrees of freedom with which $v_{\mathrm{r}}^{2}$ was determined and at the selected significance level. In the present magnetizing reduction study, $v_{\mathrm{r}}^{2}=25$ and $N=16$, accordingly $\nu_{\mathrm{c}}=1.25$. From "Student's" $t$ tables at $5 \%$ significance level, ${ }^{17)} t=2.12$, therefore $\Delta b_{j}= \pm 2.65$. A coefficient is significant if its absolute value is greater than the confidence interval, accordingly, the coefficients $a_{4}$ through $a_{15}$ are insignificant. The model is then reduced to the following formula;

$$
Y=35.81+3.69 X_{1}+9.69 X_{2}+3.69 X_{3}
$$

\subsection{Testing Adequacy of the Model}

This step is performed for the purpose of checking how fit is the model to the experimental results. In this context the residual sum of squares is quite suitable for characterizing the mean scatter relative to the line of regression. In order to remove the effect of the number of trials, the residual sum of squares is divided by the number of degrees of freedom and termed hereinafter as the variance of adequacy $\left(v_{\mathrm{ad}}^{2}\right)$

$$
v_{\mathrm{ad}}^{2}=\left\{\sum_{i=1}^{N} \Delta Y_{i}^{2}\right\} / f
$$

where $f$ is the number of degrees of freedom and equals $N-(k+1)$, where $k$ is the number of variables worked on. A ratio has been developed in statistics that is very convenient for testing a hypothesis on the adequacy of the model. It is called Fisher ratio (or $F$ ratio) and is determined by the following formula;

$$
F=v_{\mathrm{ad}}^{2} / v_{\mathrm{r}}^{2}
$$

The convenience of using the $F$ ratio consists in that the testing of a hypothesis can be reduced to comparison with a tabulated value. ${ }^{17)}$ The calculated value of $F$, i.e. $F_{\text {cal }}$, can be derived from the following formula;

$$
v_{\mathrm{ad}}^{2}=\left\{\sum_{i=1}^{N} Y_{i}^{2}-N \sum_{j=0}^{k} a_{k}^{2}\right\} / f v_{\mathrm{r}}^{2}
$$

Accordingly, $F_{\text {cal }}=0.4327$. On the other hand, from the table of $F$ ratio values at $1 \%$ significance level, $F_{\text {tab }}=$ 3.94. Since the calculated value of the $F$ ratio does not exceed the tabulated one, then with the corresponding confidence probability the model is considered adequate.

\subsection{Interpretation of the Model}

Up to now the model, given by Eq. (5), has been derived and the significance of coefficients as well as the adequacy of the model has been tested using an abstract mathematical language. Translation of the model into an experimental language includes the estimation of the magnitude and direction of the influence of separate factors and their interactions. The value of the regression coefficient is a quantitative measure of its influence on the optimization parameter. The higher the value of the coefficient, the greater is the influence of a factor. The nature of the influence of the factors is shown by the signs of the coefficients. Accordingly, the derived model indicates that, in the ranges of factors studied, reduction time has a greater positive influence on the reduction percent than both reduction temperature and gas flow rate whereas, ore particle size has a relatively insignificant effect. It is important to emphasize that the above findings are not general but rather valid only in the range of the predetermined levels of factors. It is also worthmentioning that the absolute values of the regression coefficients grow with an increase in the intervals whereas their signs remain invariant to the change in the intervals. Multiplying the coefficients of the model (Eq. (5)) and the relevant intervals presents the values by which variation in the factors values will keep the movement just along the gradient of the optimum. If the values are so big that they may increase the probability of skipping the region of the optimum, their absolute values can all be multiplied by any appropriate fraction in order to reduce the values of the movement steps and at the same time keep the relevant ratios of the original values. This property can be used in searching for the "optimum" using the steepest ascent mothod.

The calculation of the multiplication of the regression coefficient and the relevant interval for magnetizing reduction experiments is as follows:

- Temperature, $\Delta T=184.5^{\circ} \mathrm{C}$ 
- Time, $\Delta t=96.9 \mathrm{~min}$

- Flow rate, $\Delta F=3.69 \mathrm{l} / \mathrm{min}$

- Size, $\Delta S=0.2425 \mathrm{~mm}$

It is clear that the above figures are so big as movement steps that adopting them may result in missing the optimum point. Taking a movement step of $20^{\circ} \mathrm{C}$ for the temperature factor seems to be a quite proper choice. This means that $\Delta T$ has been reduced by a factor of $20 / 184.5=0.108$ which can be rounded off to 0.1 . By multiplying $\Delta T, \Delta t, \Delta F$ and $\Delta S$ by 0.1 , the values of displacements for the different factors are reduced to:

$$
\begin{array}{ll}
\Delta T=18.5^{\circ} \mathrm{C} & \Delta t=9.7 \mathrm{~min} \\
\Delta F=0.37 l / \mathrm{min} & \Delta S=0.02 \mathrm{~mm}
\end{array}
$$

Accordingly, the recommended values of the main effective factors or rather the optimum conditions are:

\section{temperature $470^{\circ} \mathrm{C}$, time $30 \mathrm{~min}$ and gas flow rate $3.5 \mathrm{l} / \mathrm{min}$}

Consulting these conditions with the "priori" information obtained from the results of the sixteen magnetizing reduction runs indicates that the conditions are convenient, since they are less powerful than those producing over-reduction to wustite and more powerful than the conditions produced magnetite. An experiment performed with the above mentioned optimum conditions showed a weight loss of $54 \%$ without overreduction of hematite to wustite. This is a very good result if we compare it with the calculated theoretical weight loss value of $55.9 \%$.

\subsection{Optimization of Magnetic Separation}

The reduced samples were subjected to magnetic separation in order to get an iron rich concentrate. Experimental design has been exercised on the experimental results using three factors; reduction temperature, reduction time and ore particle size while recovery of iron in the magnetic fraction was taken as the optimization parameter. The basic levels of the factors were chosen as follows:

- reduction temperature, $Z_{1}^{\circ}=450^{\circ} \mathrm{C}$

- time of reduction, $Z_{2}^{\circ}=10 \mathrm{~min}$

- ore particle size, $Z_{3}^{\circ}=0.25-0.125 \mathrm{~mm}$

The upper and lower levels of the factors are:

$Z_{1} 400,500^{\circ} \mathrm{C} \quad Z_{2} 5,15 \mathrm{~min} \quad Z_{3} 0.5-0.125,-0.125 \mathrm{~mm}$

Accordingly the variation intervals are:

$$
\Delta Z_{1}=50^{\circ} \mathrm{C}, \quad \Delta Z_{2}=5 \mathrm{~min} \text { and } \Delta Z_{3}=0.125 \mathrm{~mm}
$$

Table 5 shows the experimental conditions of the eight runs whose data were used for experimental design. The design matrix is given in Table 6 where the following factors interactions are considered:

$$
\begin{array}{ll}
Z_{4}=Z_{1} Z_{2} & Z_{5}=Z_{1} Z_{3} \\
Z_{6}=Z_{2} Z_{3} & Z_{7}=Z_{1} Z_{2} Z_{3}
\end{array}
$$

The regression model equation can be written as follows:

$$
\psi=c_{0}+c_{1} Z_{1}+c_{2} Z_{2}+\cdots+c_{m-1} Z_{m-1}
$$

The coefficients of the model are calculated using the
Table 5. Values of experimental factors and the corresponding optimization parameters for magnetic separation.

\begin{tabular}{|c|c|c|c|c|}
\hline Trial no. & $Z_{1}$ & $Z_{2}$ & $Z_{3}$ & $\psi$ \\
\hline 1 & 400 & 5 & 0.125 & 79 \\
\hline 2 & 400 & 5 & $0.5-0.125$ & 92 \\
\hline 3 & 400 & 15 & 0.125 & 77 \\
\hline 4 & 400 & 15 & $0.5-0.125$ & 87 \\
\hline 5 & 500 & 5 & 0.125 & 81 \\
\hline 6 & 500 & 5 & $0.5-0.125$ & 98 \\
\hline 7 & 500 & 15 & 0.125 & 78 \\
\hline 8 & 500 & 15 & $0.5-0.125$ & 80 \\
\hline
\end{tabular}

Table 6. Design matrix for magnetic separation.

\begin{tabular}{|c|c|c|c|c|c|c|c|c|c|}
\hline Trial no. & $Z_{0}$ & $Z_{1}$ & $Z_{2}$ & $Z_{3}$ & $Z_{4}$ & $Z_{5}$ & $Z_{6}$ & $Z_{7}$ & $\psi$ \\
\hline 1 & + & - & - & - & + & + & + & - & 79 \\
\hline 2 & + & - & - & + & + & - & - & + & 92 \\
\hline 3 & + & - & + & - & - & + & - & + & 77 \\
\hline 4 & + & - & + & + & - & - & + & - & 87 \\
\hline 5 & + & + & - & - & - & - & + & + & 81 \\
\hline 6 & + & + & - & + & - & + & - & - & 98 \\
\hline 7 & + & + & + & - & + & - & - & - & 78 \\
\hline 8 & + & + & + & + & + & + & + & + & 80 \\
\hline
\end{tabular}

formula previously given in Eq. (1) to get the following values:

$$
\begin{array}{llll}
c_{0}=84 & c_{1}=0.25 & c_{2}=-3.5 & c_{3}=5.25 \\
c_{4}=-1.75 & c_{5}=-0.5 & c_{6}=-2.25 & c_{7}=-1.5
\end{array}
$$

Testing the significance of the coefficients is performed for a variance of reproducibility $v_{\mathrm{r}}^{2}=12$ and $N=8$ to get a variance of the regression coefficients (according to Eq. (3)) $v_{c}^{2}=1.5$. From "Student's" $t$ table the corresponding value of $t$ equals 2.306. The confidence interval can be calculated from Eq. (4), then $\Delta b_{j}= \pm 3.25$. Accordingly, the regression coefficients $c_{1}, c_{4}, c_{5}, c_{6}$ and $c_{7}$ are insignificant. The model is then reduced to:

$$
\psi=84-3.5 Z_{2}+5.25 Z_{3}
$$

The procedure of testing the adequacy of the model (Eqs. (6)-(8)) has been performed to get the values of $F_{\text {cal }}$ and $F_{\text {tab }}$ as 1.43 and 6.3 respectively. Therefore, the model is proved to be adequate. The displacements of the factors' levels to move toward the optimum are:

$$
\Delta t=-17.5 \mathrm{~min} \text { and } \Delta S=0.6563 \mathrm{~mm}
$$

In order to get values relevant to the basic level values of the factors, 0.2 of the above values are considered. Accordingly, $\Delta t=-3.5 \mathrm{~min}$ and $\Delta S=0.13 \mathrm{~mm}$. The recovery of iron in the magnetic fraction reaches $94 \%$.

A look at Table 5 indicates that run number 6 for samples of a size $-0.5+0.125 \mathrm{~mm}$ reduced at $500^{\circ} \mathrm{C}$ for $5 \mathrm{~min}$ resulted in a relatively unprecedenting iron recovery of $98 \%$. From the statistical point of view, this ubrupt high value of iron recovery is an odd single value compared to the iron recovery values obtained for runs performed at neighbouring conditions. Nevertheless, the model points out that, with relevance to the basic levels of factors $(t=10 \mathrm{~min}, S=0.25-0.125 \mathrm{~mm}$ ), decreasing 
time and increasing particle size are favourable and lead to better iron recovery values. This is a movement of the experimental conditions towards the optimum which is at the same time a displacement of the factors's values to be closer to conditions of run number 6 , a matter which manifests the efficiency of the model.

\section{Conclusions}

(1) The quality of Egyptian iron ores can be greatly improved by being subjected to magnetizing reduction followed by magnetic separation technique. A great deal of impurities are removed and the iron content is pronouncingly increased.

(2) Most of manganese in the iron ore is directed to the non-magnetic fraction. However, it was noticed that getting a higher removal of manganese is on the expense of a relatively lower iron recovery in the magnetic fraction.

(3) Experimental design is efficiently used in the magnetizing reduction and magnetic separation processes in order to study the simultaneous effect of variables such as ore particle size, reduction temperature, reduction time and gas flow rate on both the reducibility of the ore and the iron recovery in the magnetic fraction.

(4) One more advantage of the experimental design procedure over the traditional experimental technique is getting a model which correlates the different experimental condition values to the optimization parameter. A model has been developed correlating the reduction temperature, time and gas flow rate to the reduction extent whereas another model was deduced correlating the ore size and reduction time to the iron recovery in the magnetic fraction.

\section{REFERENCES}

1) C. L. Loo and N. J. Bristow: Trans. Inst. Min. Metall. C, 103 (1994), May-Aug., 126.

2) S. Parakash: Ironmaking Steelmaking, 21 (1994), No. 3, 237.

3) S. K. Dutta and A. Ghosh: ISIJ Int., 33 (1993), No. 10, 1104.

4) M. J. Proctor, R. J. H. Hawkins and J. D. Smith: tronmaking Steelmaking, 19 (1992), No. 3, 194.

5) A. A. El-Geassy, F. O. El-Kashif, M. I. Nasr and A. A. Omar: ISIJ Int., 34 (1994), No. 7, 541.

6) G. G. O. O. Uwadiale: Miner. Processing and Extractive Metall. Rev., 11 (1992), 1.

7) G. G. O. O. Uwadiale and R. J. Whewell: Metall. Trans., 19B (1988), Oct., 731.

8) A. Modaressi, H. El-Abdouni and J. J. Heizmann: Reactiv. Solids, 7 (1989), 19.

9) H. El-Abdouni, A. Modaressi and J. J. Heizmann: Reactiv. Solids, 5 (1988), 101.

10) F. Adam, F. Jeannot, B. Dupre and C. Gleitzer: Reactiv. Solids, 5 (1988), 115.

11) M. El-Tabirou, B. Dupre and C. Gleitzer: Metall. Trans., 19B (1988), 311.

12) M. I. Nasr: Scand. J. Metall., 23 (1994), 209.

13) P. K. Sahoo and K. Srinivasa Rao: Int. J. Miner. Process., 25 (1989), 147.

14) W. A. Griffith: Chapter 12 in 60th Ann. of Froth Flotation, ed. by D. W. Fuerstenau, AIME, New York, (1962).

15) K. Zhong, T. V. Vasudevan and P. Somasundaran: Miner. Eng., 4(5/6) (1991), 563

16) F. Veglio, A. Pagliarini and L. Toro: Int. J. Miner. Process., 39 (1993), 87.

17) R. H. Perry and C. H. Chilton: Chemical Engineers' Handbook, 5th Ed., McGraw Hill, New York, (1973). 